\title{
Recent Advances in the Straps/Strips Technique for Out-of- plane Strengthening of Load-bearing Masonry Walls
}

\author{
Elena Ferretti ${ }^{\mathrm{a}} 1$ \\ ${ }^{a}$ Department of Civil, Environmental and Materials Engineering_DICAM, Alma Mater Studiorum Università di Bologna, Viale del \\ Risorgimento 2, 40136 Bologna, Italy
}

\begin{abstract}
As is well known, the main contribution of the FRP strips to the strength of load-bearing walls is an improvement in the inplane strength. This paper deals with the possibility of applying the FRP strips in way to modify the strengthening mechanism of the FRP reinforcing system, from an in-plane to an out-of-plane strengthening mechanism. In order to achieve this goal, a second reinforcement system - derived from the CAM system (Active Confinement of Masonry) - provides connections between the FRP strips placed on the opposite sides of the wall. This new strengthening technique - called the straps/strips technique - establishes a stiffness constraint that forces the opposing FRP strips to behave like two flanges of an FRP I-beam embedded in the wall. Consequently, the use of FRP strips also improves the flexural strength of the wall. The present paper briefly summarizes the results obtained in previous works with the straps/strips technique and proposes an improvement of this strengthening technique, based on some weak-points emerged in the early experimentations. The paper also shows the results of a further experimental test, performed with the improved straps/strips technique. Finally, the similarity between FRP strips with transversal connection and concrete wythes of a sandwich panel with flexible connectors leads to interpret the behavior of the ideal I-beam in terms of composite action established between the FRP strips. This paves the way for analytical modeling of the straps/strips technique.
\end{abstract}

(C) 2020 The Authors. Published by Elsevier B.V.

This is an open access article under the CC BY-NC-ND license (http://creativecommons.org/licenses/by-nc-nd/4.0/) Peer-review under responsibility of the VCSI1 organizers

Keywords: Masonry walls; Out-of-plane strengthening; FRP strips; Active strengthening techniques; Degree of Composite Action ( DCA ) .

\footnotetext{
* Corresponding author. Tel.: +39-051-209-3515; fax: +39-051-209-3495

E-mail address: elena.ferretti2@unibo.it
} 


\section{Introduction}

The use of fiber-reinforced polymer (FRP) materials in civil structures has long been attractive due to the noncorrosive properties of FRP as reinforcement. FRP is an attractive choice for civil engineering applications also because it is often cost-effective, easy and quick to install, and does not significantly affect the mass or geometry of a structure. The most common use of FRP in civil engineering is as reinforcing bars or pre-stressing strands in new precast concrete structures. Early applications of FRP for internal reinforcement in precast concrete structures date back to the nineties [Rizkalla and Tadros (1994)].

Over time, considerable research and development efforts have highlighted some critical aspects of FRP materials. As far as FRP bars are concerned, for example, increasing the diameter of the bar has the tendency to reduce their overall effectiveness due to the shear lag mechanism required to activate all the fibers within the bar cross-section [Rizkalla et al. (2013)]. This led to reduce the size of bars and develop new products, such as grid configurations with small diameter strands, which utilize the fibers more effectively.

In load-bearing precast concrete sandwich panels - consisting of two concrete wythes separated by a nonstructural insulation layer - FRP grid shear connectors (which are flexible) have recently replaced steel pin connectors and solid concrete zones (which are both rigid) to reduce thermal bridging and establish the composite action of the two concrete wythes. The shear connectors allow the sandwich panels to support both gravity loads and lateral loads due to wind [Taher (2019)], as well as to seismic [Belghiat et al. (2018)], impact [Bonacho and Oliveira (2018); Lonetti and Maletta (2018); Pham and Hao (2016); Pourfalah et al. (2018); Sauer et al. (2019)], and blast [Alsayed et al. (2016); Goswami and Adhikary (2019); Li et al. (2019); Michaloudis and Gebbeken (2019); Russo et al. (2019)] events. Actually, using any type of connectors increases the degree of composite action ( $D C A$ ), that is, the ratio between the moment of inertia of the sandwich panel with flexible shear connectors and the moment of inertia of the same sandwich panel with rigid shear connectors, providing a full-composite behavior. The increase in DCA between two concrete wythes increases the structural capacity of a precast concrete sandwich panel, making it more structurally efficient [Hodicky et al. (2015)].

The DCA value depends on the shear force transferred through the shear connectors between the two wythes. In particular, full-composite and non-composite cases transfer 100\% $(D C A=1)$ and $0 \%(D C A=0)$ of the shear forces, respectively [Lorenz and Stockwell (1984)]. DCA values between 0 and 1 (partial DCA) are typical of flexible shear connectors (FRP connectors), since the slip due to the inadequacy of flexible shear connectors to maintain strain compatibility causes a decrease in the $D C A$ value with respect to the ideal case $D C A=1$ (rigid headed steel studs).

Based on the idea of composite structural action provided by the flexible shear connectors, Ferretti (2018b) proposed to establish a connection between two flat FRP reinforcements applied on the two sides of a masonry wall, so that flat FRP reinforcements - useful to provide an in-plane strengthening - can also improve the outof-plane strength of walls. In particular, the straps/strips technique proposed in Ferretti (2018b) deals with the possibility of providing a wall with out-of-plane strengthening using vertical CFRP (Carbon Fiber-Reinforced Polymer) strips as surface flat reinforcement and some loop-shaped straps of a continuous tying system derived from the CAM system (Active Confinement of Masonry) as connectors (Fig. 1). A suitable insulating plaster on the straps can then avoid thermal bridges.

The CAM straps differ from any other connector since the CAM system is an active strengthening system, which means that the straps have a pre-tension that does not depend on the loads beard by the wall [Cilia et al. (2015); Dolce et al. (2009, 2008, 2001); Ferretti (2018a); Leonori and Vari (2015); Marnetto (2007); Marnetto and Vari (2015); Marnetto et al. (2014)]. The more stiff and pre-tensioned the CAM straps, the more rigid the connections between the CFRP strips. Higher values of stiffness and pre-tension also delay the delamination at the interface between wall and CFRP strips. Furthermore, being a continuous three-dimensional strengthening system, the CAM-derived net of straps also offers good box-type behavior.

As with load-bearing precast concrete sandwich panels, the connector stiffness of the straps/strips technique affects the flexural strength of the wall [Ferretti (2019, 2018b); Ferretti and Pascale (2019a, 2019b)] and a $D C A$ value between 0 and 1 still provides the measure of the effectiveness of the reinforcement. The experimental results discussed in the following sections refer to walls made of brick masonry, but the straps/strips technique is also useful for increasing the out-of-plane strength of load-bearing walls made with any other material. 


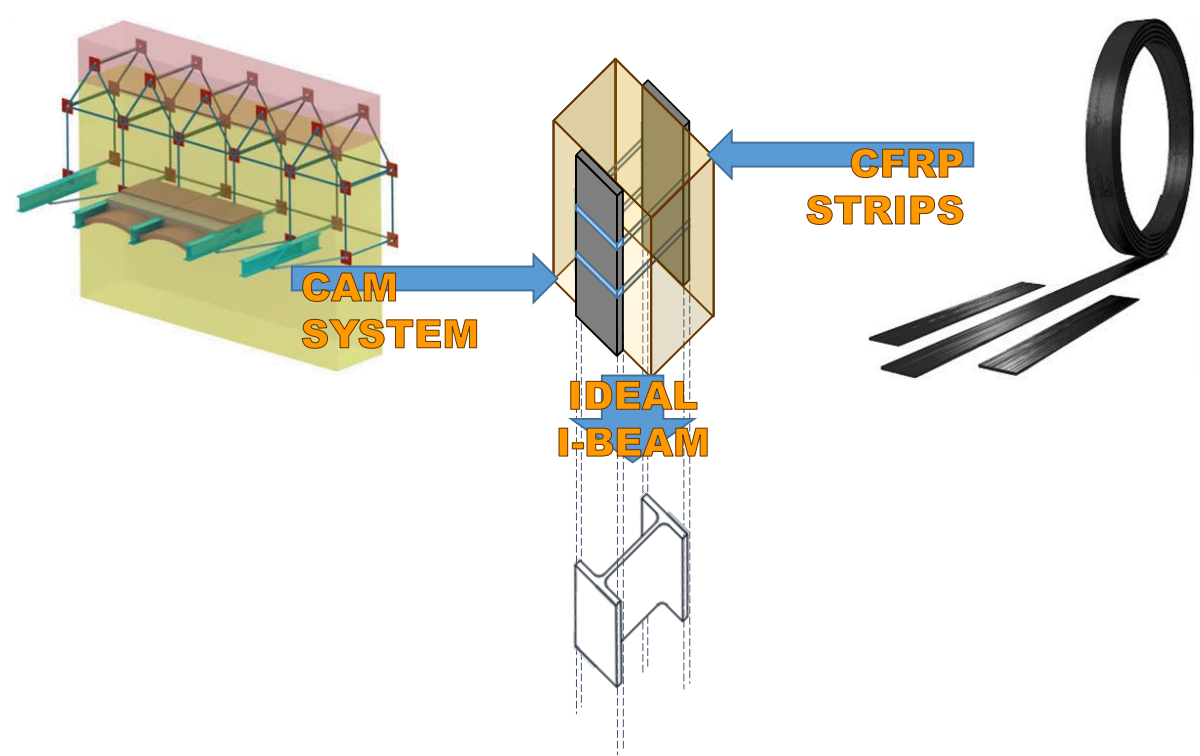

Fig. 1. The ribbons of the CAM-like system acts on the CFRP strips as shear connectors, providing a bracing effect in the thickness of the wall that is similar to that given by an embedded I-beam.

\section{The straps/strips technique: general principles and first results}

The experimental program described in Ferretti (2019) and Ferretti and Pascale (2019a,b) is the first ever performed on masonry walls strengthened with the straps/strips technique described in Section 1 . The twofold objective of this experimentation is:

- To verify whether establishing shear connections between flat strengthening systems applied on the two sides of a load-bearing wall can improve the out-of-plane strength of the wall;

- To compare the effectiveness of shear connections with different stiffnesses.

As this experimentation deals with the mechanical characterization of a combined strengthening technique (Fig. 1), there are two reference specimens, that is, a reference specimen for each of the two strengthening systems combined in Fig. 1. In particular, the reference specimen for the CAM system is Specimen W1, a brick masonry wall reinforced by steel ribbons that pass through some holes made in the wall (Fig. 2). In order to minimize the number of holes, the arrangement of the holes of Specimen W1 follows the quincunx pattern (Fig. 2). This causes the steel ribbons to form two staggered three-dimensional nets.

As in the left scheme of Fig. 1, the steel ribbons form closed loops, obtained by overlapping and securing together the ends of the ribbons. This allows the fastening system to provide a pre-tension to the ribbons, which therefore behave like straps that compress the masonry. Since the pre-tensioning of the straps can damage the bricks at the corners of the loops made by the ribbons, some protection elements (Fig. 3) prevent the concentration of the forces at the points of contact between straps and bricks.

The reference specimen for the CFRP strips is Specimen W2, a brick masonry wall with two CFRP strips applied vertically on the two sides of the wall, along the centerlines of the wall (Fig. 2). The two CFRP strips are $50 \mathrm{~mm}$ wide and $1.2 \mathrm{~mm}$ thick.

Specimens W1 and W2 have the same dimensions and arrangement of the bricks. The load/deflection curves of the two specimens in three-point bending (Fig. 4) are consistent with the characteristics of the two strengthening systems. That is, the steel ribbons do not increase the maximum load - which is the same as that of the unreinforced specimen - but provide the specimen with a high degree of ductility. In contrast, the CFRP strips double the maximum load, but have a brittle behavior. 

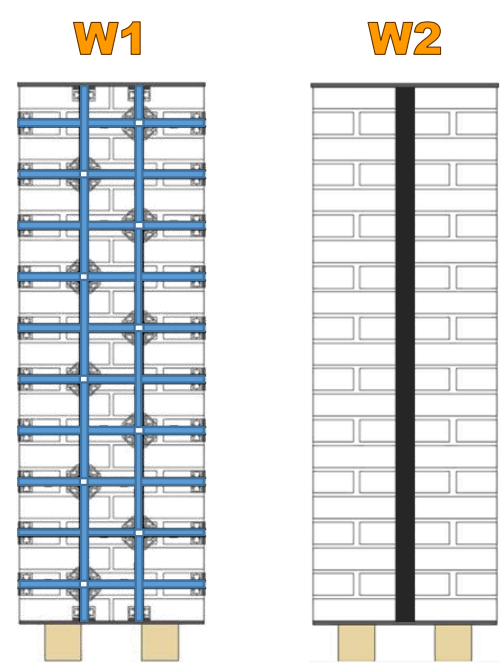

Fig. 2. The two reference specimens of the experimentation.

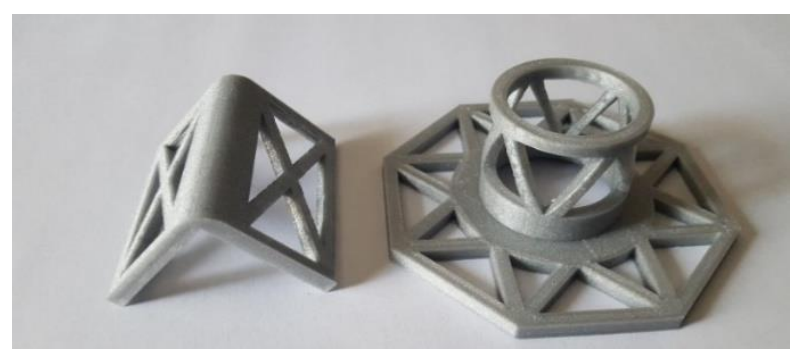

Fig. 3. 3D printed funnel-shaped plates and rounded angles to protect the bricks at the corners of the straps.

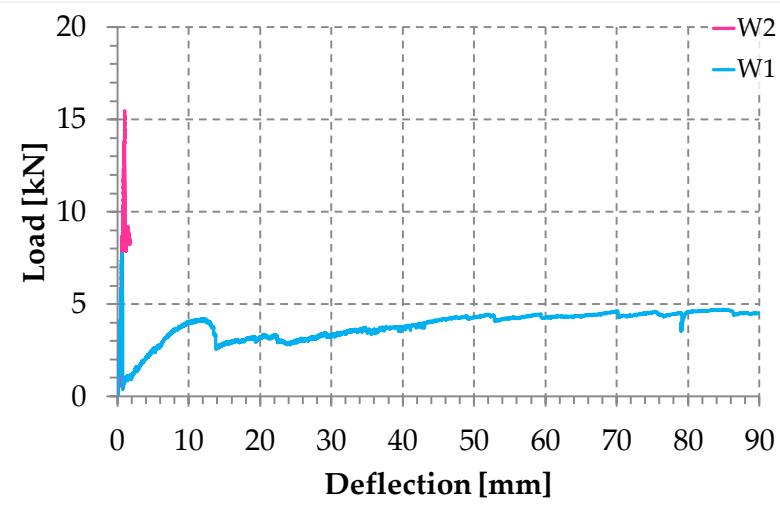

Fig. 4. Load/deflection curves of the reference specimens tested in three-point bending.

The purpose of the straps/strips technique is to exploit the advantages of both strengthening techniques: the ductility of the CAM system and the increase in strength provided by the CFRP strips. Fig. 5 shows the arrangement of the steel ribbons for the first two specimens strengthened with the straps/strips technique. The two specimens differ in the number of straps in the central parts, where the bending moment is greater. In both cases, however, the strengthening sequence is as follows: gluing the CFRP strips, applying all the straps parallel to the shorter sides (transverse straps), and applying the straps parallel to the longer sides (longitudinal straps). 

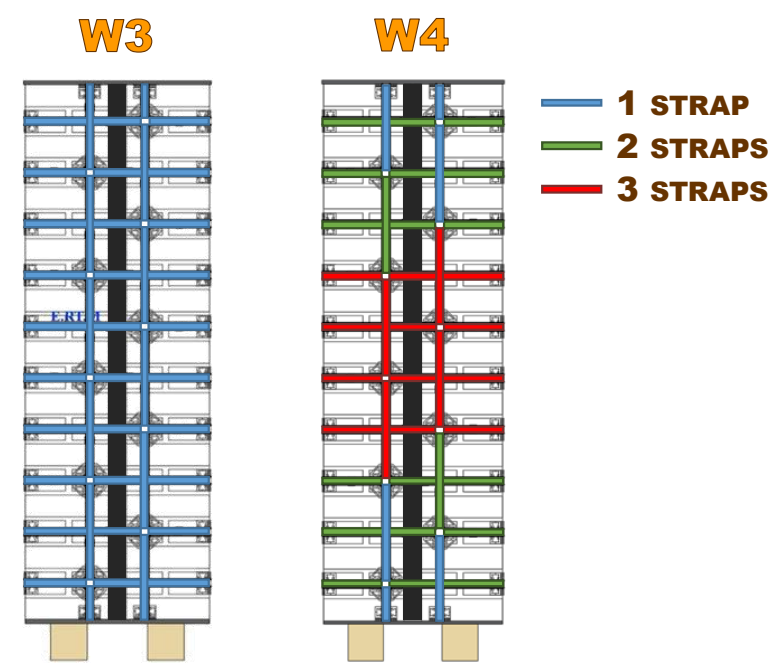

Fig. 5. The two specimens with straps made of steel ribbons (same dimensions and arrangements of the bricks as for specimens W1 and W2).

The reason for this sequence lies in the action that the transverse straps must exert on the CFRP strips: in order for the transverse straps to supply symmetrical loads to the CFRP strips (Fig. 6), the longitudinal straps pass over the transverse straps and push them against the masonry wall, in a symmetrical position with respect to the holes. The two symmetrical loads firmly block the CFRP strips on the masonry wall, thanks to the mechanical bond provided by the interface friction forces. This delays the CFRP delamination - which occurs due to the shear forces at the interface - and increases the delamination load. In particular, the increase in the delamination load is greater the greater the pre-tension and the stiffness of the straps. Moreover, the delamination load increases with the number of straps per loop.

Finally, the compression force supplied by the transverse straps to the CFRP strips also provides the CFRP strips with a DCA after the delamination load. This allows the CFRP strips to establish an I-beam behavior even after delamination, although with a reduced stiffness of the shear connection. In fact, before delamination, both the chemical bond provided by the resin and the mechanical bond provided by the friction contribute to establishing the shear connection while, after delamination, only the friction effect remains active.

a)

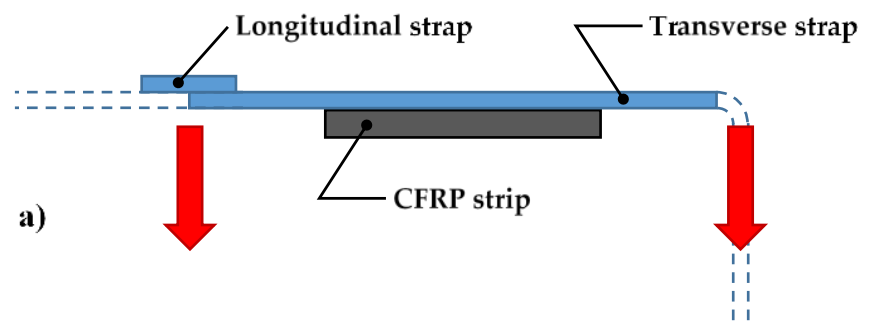

b)

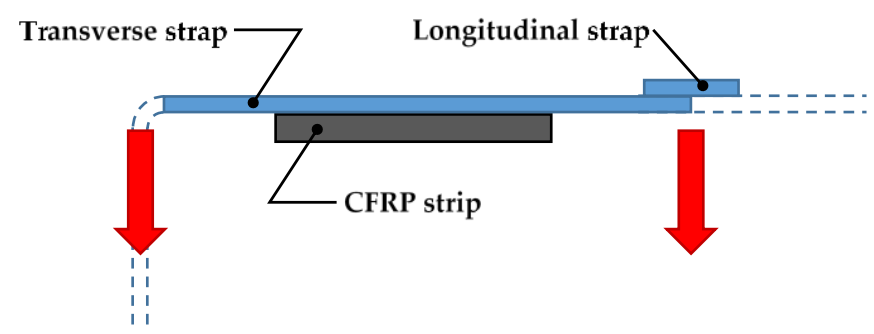

Fig. 6. Symmetrical loading of the CFRP strip: the longitudinal strap pushes down on the transverse strap to the left (a) and to the right (b) of the CFRP strip (cross-section view, not to scale). 


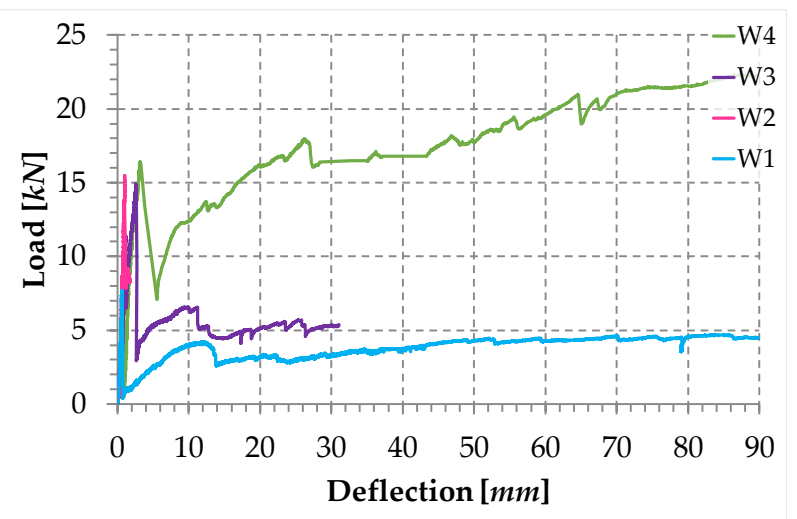

Fig. 7. The load/deflection curves of specimens W1, W2, W3, and W4, tested in three-point bending.

The DCA effect established by the straps after delamination is easily recognizable in the load/deflection curves of Fig. 7. In fact, compared to Specimen W1, specimens W3 and W4 show a post-delamination increase in load that finds an explanation precisely in the I-beam behavior allowed by the straps. In particular, the greater number of straps of Specimen W4 increases the post-delamination DCA, providing the specimen with a resilience comparable to that of CFRP-wrapped columns [Rousakis et al. (2019); Ferretti (2012, 2005)]. However, since the bending stiffness of the steel ribbons is very low, the mechanical bond established by the friction forces is negligible with respect to the chemical bond of the resin. Therefore, the steel ribbons do not affect the pre-delamination $D C A$ and the three delamination loads in Fig. 7 are almost the same.

In order to increase the pre-delamination $D C A$ - and, consequently, the delamination load - the strapping technique of Specimen W5 uses steel wire ropes instead of steel ribbons. Also in this second case, the fastening system provides a pre-tension to the steel elements, which therefore act as straps. The straps of Specimen W5 pass through holes arranged as for specimens W1, W3, and W4 (Fig. 8a).

Due to the higher carbon content in the composition, the strength of the steel wire is significantly higher than the strength of structural steels. However, the ductility of the steel wire ropes is lower than that of the structural steel [Llorens (2015)]. For comparison purposes, the steel wire ropes of the experimentation have the same yield load as the steel ribbons (about $5 \mathrm{kN}$ ).

Fig. 8a shows the number and arrangement of the straps for Specimen W5. The number of straps per loop in the central part of the specimen is 2 , to have more straps that resist the load where the bending moment is greater (as for Specimen W4).

a)

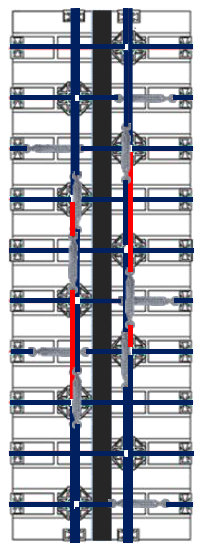

\section{STRAP} - 2 STRAPS

Fig. 8. Strapping with steel wire ropes: a) arrangement of the straps in Specimen W5 and b) load/deflection curves of specimens with different strengthening systems.

The comparison between the load/deflection diagrams of Specimens W4 and W5 (Fig. 8b) clarifies the contribution of the stiffness of the straps on the pre-delamination $D C A$. In fact, the steel wire ropes have a twofold effect on the structural behavior: they significantly increase the delamination load and make Specimen W5 as stiff as Specimen W2 - the specimen strengthened only with the CFRP strips - up to the delamination load of Specimen W2. Therefore, the steel wire ropes induce the specimen to benefit from the pre-delamination DCA up to loads higher than those allowed by the steel ribbons. In particular, the delamination load of Specimen 
W5 is approximately $239 \%$ of the delamination load of Specimen W2, while that of Specimen W4 is almost equal to the delamination loads of specimens W2 and W3, despite the greater number of straps compared to Specimen W3.

After delamination, the load/deflection curve of Specimen W5 falls on the curve of Specimen W4, which confirms that the two strengthening systems resist the load in the same way in the central part of the specimens, where the bending moment is greater. However, due to the low ductility of the steel wire ropes, several longitudinal straps suffered fraying during the test, in particular those positioned on the middle cross-section. For the deflection value of about $47 \mathrm{~mm}$, the fraying became no longer sustainable by the remaining steel wires and the longitudinal straps started to break in slow succession.

Despite the positive effects on the DCA, further improvements are possible to make the straps/strips technique even more efficient [Ferretti (2019)]. In particular, the modified straps/strips technique presented in Section 3 is a first attempt to provide a solution to the following two shortcomings:

- The breakage of one or more funnel-shaped elements compromises the chain of the longitudinal straps.

- An excessive post-delamination fraying of the steel wire ropes can cause the structural element to collapse.

\section{The modified straps/strips technique}

The funnel plates and rounded angles in Fig. 3 form part of the experimental program on the straps/strips technique. They are 3D printed elements made with PLA (Polylactic Acid), a thermoplastic, biodegradable, and non-toxic polyester. These protection elements replace the patented protection elements of the CAM system (Fig. 9) for the unlimited range of shapes that the 3D technology can offer compared to the traditional hot forming technique. This makes the 3D technology less expensive in those cases that require the use of elements with very specific geometric characteristics, like those in Fig. 3. Furthermore, the PLA filament is one of the most eco-friendly 3D printer materials available because the polymerized lactic acid comes from annually renewable resources (cornstarch, tapioca roots, sugarcane, or other sugar-containing crops).

PLA is very robust when adequately protected against degradation. In fact, the damage suffered by the protection elements of Fig. 3 during the tests was often so low as to allow their reuse. Near the cross-sections of failure, however, some straps broke the funnel elements (Fig. 10a), also tearing the bricks along the walls of the perforated cavities. This made the straps partially ineffective and reduced the load-bearing capacity of the specimen.

In order to avoid undesired reductions in the load-bearing capacity due to the breakage of the protection elements, it may be useful to re-design the 3D-printed elements or use a more resistant material. The second solution is the one adopted in the modified straps/strips technique. In particular, since the previous experimental tests did not show a real need to have plates for the distribution of loads near the holes, the new protection elements for the holes are simply toroidal steel rings (Fig. 10b).

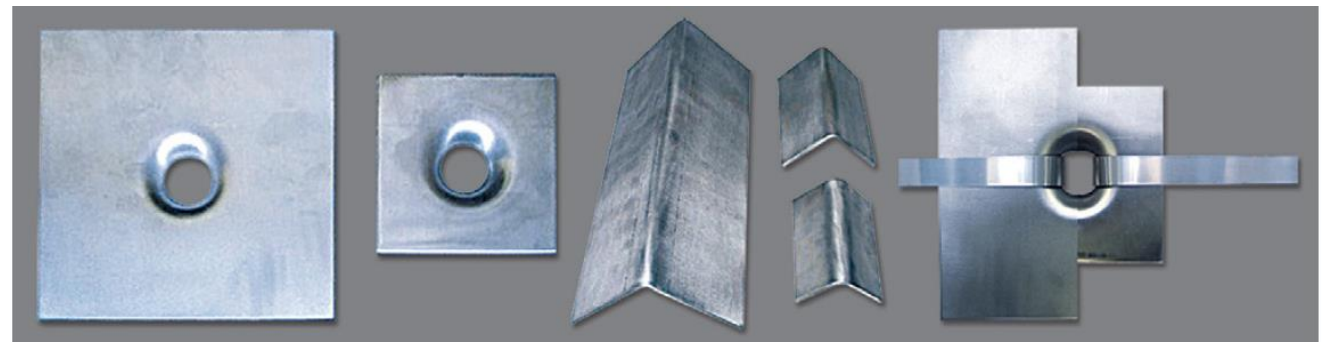

Fig. 9. Protection elements of the CAM system.
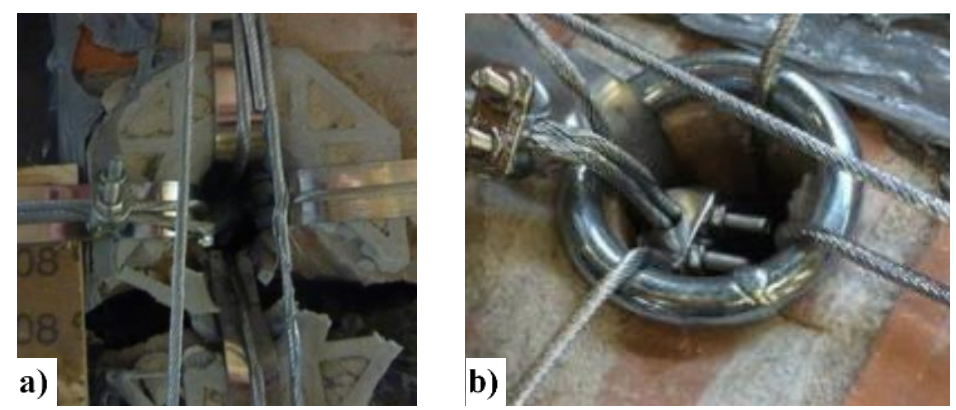

Fig. 10. Protection elements for the holes: a) the element of the first straps/strips technique and b) modified element. 

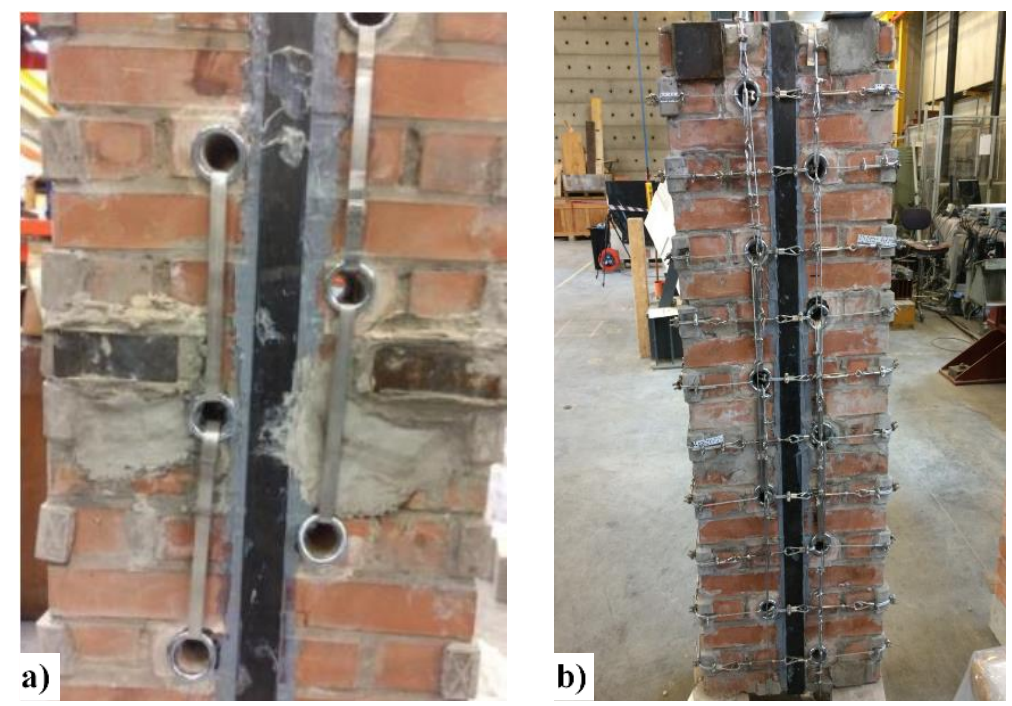

Fig. 11. Modified strapping technique: a) ribbons for the 4 longitudinal loops closest to the middle cross-section and b) ropes for all the loops.

In order to avoid even the possible structural collapse due to excessive post-delamination fraying, in addition to the longitudinal steel wire ropes, the modified straps/strips technique uses longitudinal stainless steel ribbons for the straps of the four loops closest to the middle cross-section (Fig. 11a). The additional steel ribbons do not need a pre-tension. For each of the four modified loops, one strap made of steel ribbons replaces one strap made of steel wire ropes (Fig. 11b). Therefore, since the strength of the steel wire is higher than the strength of the steel ribbon, the delamination load of the modified technique will be less than the delamination load of Specimen W5.

The label of the specimen strapped with the modified straps/strips technique is Specimen W6. The threepoint bending flexural test of Specimen W6 took place in the displacement control - after having overturned the specimen in horizontal configuration (Fig. 12) - as for the previous specimens.

The failure mechanism of Specimen W6 was the same as that of the straps/strips technique with straps made either with steel ribbons or with steel wire ropes: the masonry wall failed with a disconnection at the interface between mortar and bricks, as usual in composite systems with joints made of mortar or grouting [Ferretti (2013a)]. The mortar/brick disconnection occurred near the middle cross-section of the bent wall, for a load value lower than the delamination load. Even this result is in line with those of previous tests. In fact, as for specimens W3, W4, and W5, the longitudinal straps kept the inner disconnection closed when the joint failed (Fig. 13), allowing the CFRP strips to withstand further load increases. For Specimen W2, on the contrary, the mortar/brick disconnection load is equal to the delamination load of the two CFRP strips, that is, the maximum load in Fig. 4. Since Specimen W2 withstood only a few deflection increments beyond the maximum load, this load value also represents the crisis of the specimen. Therefore, in Specimen W2 disconnection and delamination coincided with the specimen crisis.

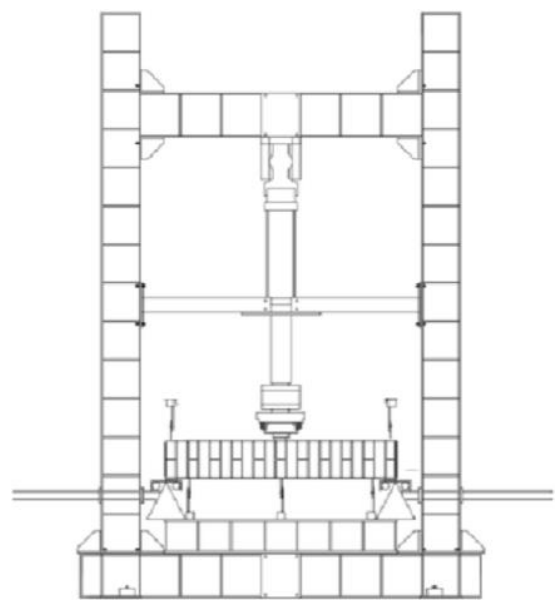

Fig. 12. Test set-up for three-point bending flexural tests. 


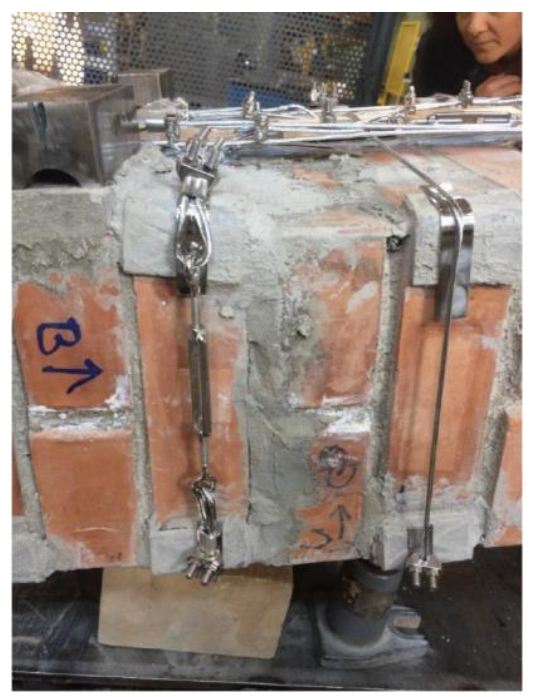

Fig. 13. Mortar/brick disconnection: the stiffness of the longitudinal straps does not allow free rotation around the inner hinge.

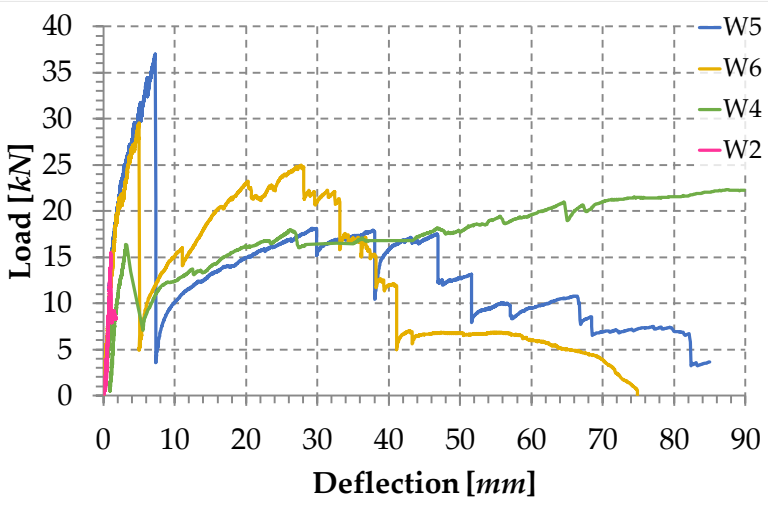

Fig. 14. Load/deflection curve of Specimen W6, compared to the results of the previous tests.

Furthermore, not even delamination actually caused the crisis of specimens W3, W4, W5, and W6. In fact, the delamination led to significant load drops, but long load-recovery branches followed the delamination peaks (Fig. 7, Fig. 14). This is due to the ductility of the longitudinal straps that, as they were yielding, allowed the disconnected parts of the specimens to rotate in a controlled way around the inner hinges generated by the disconnections.

The comparison between the load/deflection diagrams in Fig. 14 shows that the straps/strips technique with steel wire ropes meets both objectives of the experimental program. In fact, the shear connections established between the CFRP strips by the three-dimensional net of straps clearly improve the out-of-plane behavior of the wall for at least two reasons:

- The delamination loads of specimens W5 and W6 are greater than the delamination load of Specimen W2, strengthened only by CFRP strips. They are also greater than the delamination loads of specimens W3 and W4, with straps made of steel ribbons.

- The existence of post-delamination branches for Specimens W5 and W6 indicates that - as for specimens W3 and W4 - the shear connections between the CFRP strips survive the delamination. Consequently, the delamination of the CFRP strips does not coincide with the service limit of the structure. Actually, the tying systems of both specimens allow load recovery after the delamination peaks, with recovered loads greater than the delamination load of Specimen W2. Moreover, since load recovery takes place with high deflection values, Specimens W5 and W6 have ductile behaviors, while Specimen W2 is brittle. This allows Specimens W5 and W6 to provide a warning against the crisis.

As far as the specific case of the modified straps/strips technique is concerned (Specimen W6), the delamination load is lower than that of the straps/strips technique with only steel wire ropes - as expected - but in any case greater than that of the specimen strengthened only by CFRP strips. In particular, the delamination 
load of Specimen W6 is about $80 \%$ of the delamination load of Specimen W5 and 191\% of the delamination load of Specimen W2.

Despite a decreased delamination load, the load recovered at a given post-delamination deflection value is higher for Specimen W6 than for Specimen W5 (Fig. 14). This confirms the need to use the most rigid protection elements possible for the holes, to improve the efficiency of the system after delamination. In particular, the use of toroidal steel rings instead of 3D printed elements increases the post-delamination stiffness and allows a faster load recovery.

The fraying of the steel wire ropes begins first for Specimen W6 compared to Specimen W5, since the number of steel wire ropes on the middle cross-section is lower for Specimen W6 than for Specimen W5. As a result, the load recovery branch is shorter for Specimen W6 than for Specimen W5. Nevertheless, the maximum post-delamination load of specimen W6 is approximately $161 \%$ of the delamination load of specimen W2. Moreover, at the end of the load recovering branch - which corresponds to a deflection value of about $33 \mathrm{~mm}$ - the deflection of Specimen W6 is about 32 times the delamination deflection of Specimen W2.

The fraying process ends for a deflection value of about $41 \mathrm{~mm}$, with the breakage of all the steel wire ropes. However, Specimen W6 still withstands a load of about $6.8 \mathrm{kN}$, which remains almost constant for the next $16 \mathrm{~mm}$ of deflection increase. This branch of the load/deflection curve corresponds to the action of the steel ribbons that act as life-saving devices, delaying the collapse of the structure. In fact, the load value of $6.8 \mathrm{kN}$ is almost equal to the maximum post-delamination load of Specimen W3, the specimen strengthened by the straps/strips technique with only one steel ribbon per loop. Actually, the residual load is slightly higher for Specimen W6 than for Specimen W3. Once again, this depends on the greater stiffness of the toroidal steel rings compared to the $3 \mathrm{D}$ printed funnel elements, which increases the efficiency of the system even in the final part of the load/deflection curve.

The slow final unloading of Specimen W6 is a consequence of the slippage that occurred in the seals of the steel ribbons. This slippage was so high as to cause the opening of the straps (Fig. 15) and the consequent collapse of the specimen. Thus, there was no actual failure of the strengthening system, but only a malfunction of the fastening system. This means that it is possible to delay the collapse by increasing the length of the ribbons.

As a last observation, it is worth noting that specimens W1, W5, and W6 are actually the same specimen. In fact, Specimen W5 is the new label given to Specimen W1 after the three-point bending flexural test, restoration of the disconnected section and modification of the strengthening system. Analogously, Specimen W6 is the new label given to Specimen W5 after a second three-point bending flexural test, a further restoration, and the application of a new strengthening system. Fig. 16 collects the results of the three flexural tests performed on the same specimen.
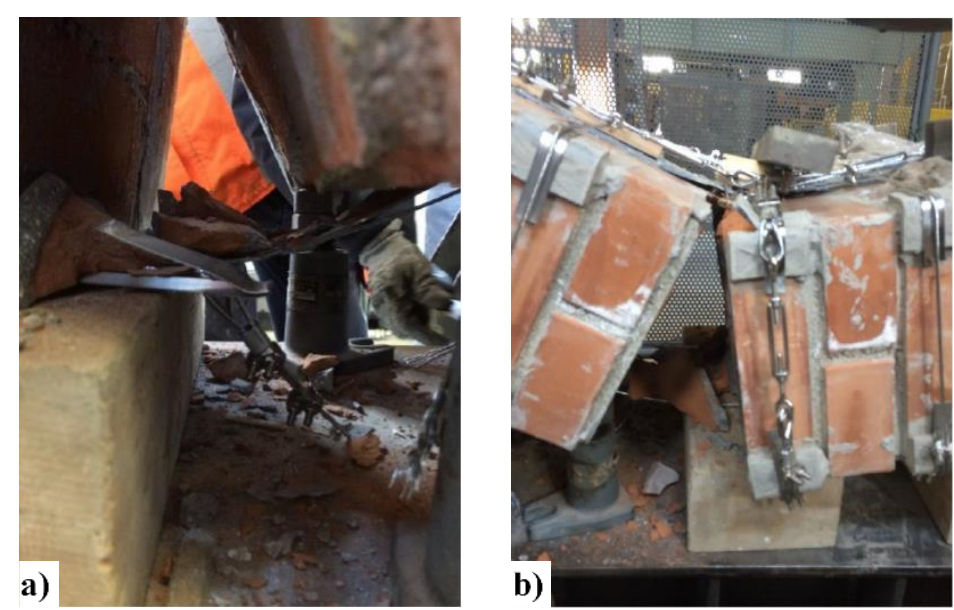

Fig. 15. Failure of the steel ribbons: a) detail of the unfastened seal in the front and b) rear view. 


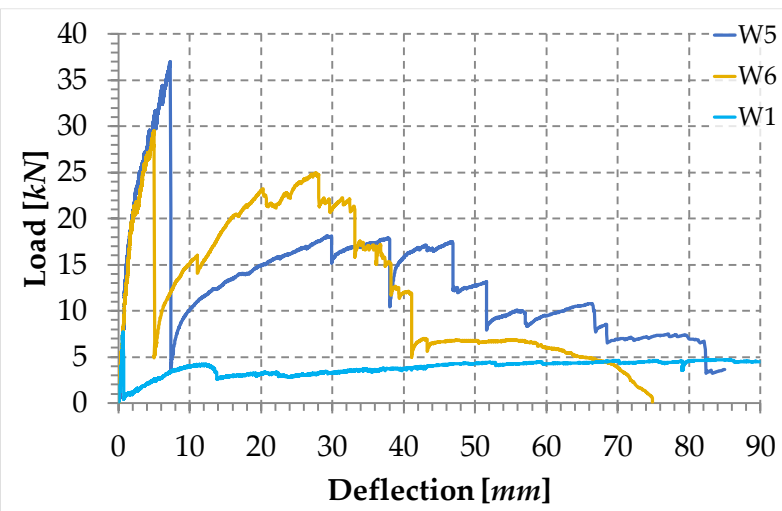

Fig. 16. The load/deflection curves for the three-point bending flexural tests performed on the same specimen.

Since the maximum load of the specimen increases by about $379 \%$ after the first restoration and by about $283 \%$ after the second restoration, the curves in Fig. 16 can ultimately provide a measure of the efficiency of the straps/strips technique as a technique of restoration.

\section{A brief note on the Degree of Composite Action (DCA) established by the straps/strips technique}

As clarified in Section 1, the DCA is a measure of the slip allowed by the flexible connectors between the concrete wythes of a sandwich panel.

There are many studies to calculate the DCA for concrete sandwich panels. Benayoune et al. (2008), for example, proposed to calculate the $D C A$ based on the stress distribution:

$$
D C A=\frac{M h}{\sigma_{b}-\sigma_{t}}
$$

where $\sigma_{b}$ and $\sigma_{t}$ are the stresses at the bottom and top faces of the panel, respectively, $M$ is the applied bending moment, and $h$ is the depth of the panel.

By analogy with the concrete sandwich panels, a definition that may briefly indicate the straps/strips technique described in Sections 2 and 3 is "FRP sandwich strips" [Ferretti (in prep.)]. In fact, the straps/strips technique introduces flexible connections (the straps) in addition to the chemical bonds of the FRP strips, which are the flat elements of the sandwich. Since delamination cancels the chemical bond, the only connections between the FRP strips after delamination are those of the flexible straps. This allows us to extend the idea of $D C A$ to the I-beam behavior obtained with the straps/strips technique. In particular, since the structural behavior changes with delamination, it is convenient to distinguish between a pre-delamination $D C A$ and a post-delamination $D C A$.

The results discussed in Sections 2 and 3 show that the pre-delamination stiffness does not change after the application of the straps, neither in the case of steel ribbons nor in the case of steel wire ropes. This means that the straps/strips technique does not improve the pre-delamination $D C A$, which depends on the properties of the resin used to glue the CFRP strips onto the masonry wall. However, the steel wire ropes have a positive effect on the composite action of pre-delamination, as they increase the delamination load, allowing the specimen to benefit of the composite action of pre-delamination for higher loads. In particular, the use of a single steel wire rope per loop increases the validity range of the pre-delamination DCA by $91 \%$ (the delamination load of Specimen W6 is $191 \%$ of the delamination load of Specimen W2). The second steel wire rope per loop increases the validity range of the pre-delamination DCA by an additional $48 \%$ (the delamination load of Specimen W5 is $239 \%$ of the delamination load of Specimen W2). Therefore, it seems that the relationship between number of straps and increase in the validity range of the pre-delamination $D C A$ is not linear.

After delamination, the masonry no longer contributes to resisting the bending moment and the residual loadbearing capacity depends on the CFRP sandwich strips. This second time, both the steel ribbons and the steel wire ropes have positive effects on the $D C A$. In fact, increasing the number of straps increases the $D C A$ in both cases.

It is worth noting that the discontinuous distribution of the transverse straps leads the $D C A$ to variate along the ideal I-beam. In fact, as in the concrete sandwich panels with punctual shear connectors (Fig. 17), the stress 
distribution is non-uniform due to the shear flexibility of the CFRP strips. However, the small thickness of the CFRP strips tends to cancel this effect on the stress distribution, called the shear-lag effect. Moreover, the collaboration between transverse and longitudinal straps leads to a further reduction of the shear-lag effect. In fact, the straps distribute the normal stress over the entire contact area between straps and CFRP strips, making the effective flange width equal to the actual width of the CFRP strips. The estimation of the actual distribution of stress and DCA along the ideal I-beam - through both analytical analyses and numerical simulations with the Cell Method [Ferretti (2013b)] - is still under evaluation [Ferretti (in prep.)].

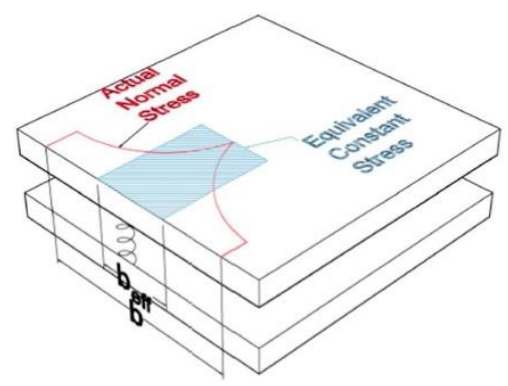

Fig. 17. Effective flange width for the transmission of the normal stresses in concrete sandwich panels with punctual shear connectors (headed steel studs): the area of the stress block with constant stress along the reduced width $b_{\text {eff }}$ is equal to the area subtended to the diagram of the actual stress distributed along the width $b$ [Yossef and Chen (2018)].

\section{Conclusions}

The use of flexible shear connectors is here extended to provide a degree of composite action ( $D C A$ ) to flat FRP reinforcements, to counteract the out-of-plane loads on load-bearing masonry walls in large deflections. The extension concerns the very nature of the flexible shear connectors, which are pre-tensioned straps derived from the CAM system. Passing over the FRP strips, the horizontal loops made by the straps establish a stiffness constraint between the FRP strips, similar to that provided by punctual shear connectors. Therefore, the tied FRP strips work as flanges of an ideal I-beam embedded into the wall, giving rise to a strengthening mechanism against out-of-plane loads. Since the web of the ideal I-beam is axially deformable, the system composed of FRP strips and deformable connectors behaves similarly to a concrete sandwich panel with flexible shear connectors. Thus, the ideal I-beam can also be referred to as FRP sandwich strips.

The I-beam behavior survives delamination, allowing the sandwich to withstand loads even when the FRP strips are detached from the masonry wall. Therefore, it is possible to define two different DCA s for FRP sandwich strips: a $D C A$ of pre-delamination and a $D C A$ of post-delamination. This is a unique prerogative of this three-dimensional strengthening technique - the straps/strips technique - as it represents the first attempt to provide a DCA to the delaminated flat FRP elements, to make the out-of-plane failure mechanism of masonry walls ductile.

Furthermore, by activating frictional forces at the interface between the wall and the FRP strips, the pretensioning of the straps has a positive action on the $D C A$ even before delamination. In fact, the frictional forces counteract the slippage between the wall and the FRP strips. Therefore, the FRP strips of the sandwich behave like two flanges of an ideal FRP I-beam even before damage occurs. This allows the wall to withstand higher out-of-plane loads before delamination, with an improvement of the out-of-plane load-bearing capacity that is proportional to the stiffness and pre-tension of the connectors. Thus, the increase in the delamination load is much more sensitive when using steel wire ropes rather than steel ribbons, which are more ductile than the steel wire ropes. The pre-tension of straps also delays the delamination of the FRP strips in terms of delamination deflection.

The experimentation carried out on CFRP strips has shown that, in order to satisfy both the requirements of increasing the delamination load and increasing the ductility, it is convenient to use both steel wire ropes and steel ribbons for the straps. In fact, despite the steel ribbons do not increase the delamination load, they are useful because of their high ductility, which allows the net of straps to retain the damaged material up to large deflections. In real buildings, this helps protect people from possible impact injuries. Therefore, the combined use of steel wire ropes and steel ribbons serves as a reinforcement system before structural damage occurs and as a protection device after structural damage has occurred. This is a remarkable achievement for the straps/strips technique, since any other strengthening system acts on a structural element increasing either strength or ductility. 
Finally, the experimentation also highlighted the key role played by the protection elements of the holes for the passage of the straps. In fact, a greater stiffness of the protection elements makes it possible to recover higher load values after the delamination peak.

\section{Acknowledgements}

The results presented here are part of the CIMEST Scientific Research on the Identification of Materials and Structures, DICAM, Alma Mater Studiorum, Bologna (Italy). The author is grateful to Antonina Udod for her active collaboration in the experimental program.

\section{References}

Alsayed, S.H., Elsanadedy, H.M., Al-Zaheri, Z.M., Al-Salloum, Y.A., Abbas, H., 2016. Blast Response of GFRP-Strengthened Infill Masonry Walls. Construction and Building Materials 115, 438-451.

Belghiat, C., Messabhia, A., Plassiard, J.-P., Guenfoud, M., Plé, O., Perrotin, P., 2018. Experimental Study of Double-Panel Confined Masonry Walls under Lateral Loading. Journal of Building Engineering 20, 531-543.

Benayoune, A., Abdul Samad, A.A., Trikha, D.N., Abang Ali, A.A., Ellinna, S.H.M., 2008. Flexural behaviour of pre-cast concrete sandwich composite panel - Experimental and theoretical investigations. Construction and Building Materials 22, 580-92.

Bonacho, J., Oliveira, C.S., 2018. Multi-Hazard Analysis of Earthquake Shaking and Tsunami Impact. International Journal of Disaster Risk Reduction 31, 275-280.

Cilia, M., Cipolla, I., Colajanni, P., Marnetto, R., Recupero, A.. Spinella, N., 2015. Prove sperimentali su travi in c.a. rinforzate con metodo CAM $^{\circledR}$ : Valutazione del comportamento a taglio. Progettazione Sismica VII, 93-108.

Dolce, M., Nigro, D., Ponzo, F.C., Marnetto, R., 2001. The CAM System for the Retrofit of Masonry Structures, 7th International Seminar on Seismic Isolation, Passive Energy Dissipation and Active Control of Vibrations of Structures, Assisi, Italy.

Dolce, M., Ponzo, F.C., Di Croce, M., Moroni, C., Giordano, F., Nigro, D., Marnetto, R., 2009. Experimental Assessment of the CAM and DIS-CAM Systems for the Seismic Upgrading of Monumental Masonry Buildings, PROHITECH 09, 1st International Conference on Protection of Historical Constructions, Rome, Italy, CRC Press/Balkema: Leiden, The Netherlands, 1021-1028.

Dolce, M., Ponzo, F.C., Goretti, A., Moroni, C., Giordano, F., De Canio, G., Marnetto, R., 2008. 3D Dynamic Tests on 2/3 Scale Masonry Buildings Retrofitted with Different Systems, 14th World Conference on Earthquake Engineering, Beijing, China.

Ferretti, E. (in prep.), FRP Sandwich Strips to Counteract out-of-Plane Loads on Load-Bearing Walls, Materials.

Ferretti, E., 2019. Wire Ropes and CFRP Strips to Provide the Masonry Walls with Out-of-Plane Strengthening. Materials 12, 2712.

Ferretti, E., 2018a. Effectiveness of Active Confinement Techniques with Steel Ribbons: Masonry Buildings. European Journal of Engineering and Formal Sciences 2, 18-30.

Ferretti, E., 2018b. Attaining a Beam-Like Behavior with FRP Strips and CAM Ribbons. European Journal of Engineering and Formal Sciences 2, 7-17.

Ferretti, E., 2013a. A Cell Method stress analysis in thin floor tiles subjected to temperature variation. CMC-Computers Materials \& Continua 36, 293-322.

Ferretti, E., 2013b. The Cell Method: An enriched description of physics starting from the algebraic formulation. CMC-Computers Materials \& Continua 36, 49-71.

Ferretti, E., 2012. Shape-Effect in the Effective Laws of Plain and Rubberized Concrete. CMC-Computers Materials \& Continua 30, 237284.

Ferretti, E., 2005. On nonlocality and Locality: Differential and Discrete Formulations, ICF11, 11th International Conference on Fracture. Turin, Italy, 1728-1733.

Ferretti, E., Pascale, G., 2019a. Combined Strengthening Techniques to Improve the Out-of-Plane Performance of Masonry Walls. Materials 12, 1171.

Ferretti, E., Pascale, G., 2019b. Some of the Latest Active Strengthening Techniques for Masonry Buildings: A Critical Analysis. Materials $12,1151$.

Goswami, A., Adhikary, S.D., 2019. Retrofitting Materials for Enhanced Blast Performance of Structures: Recent advancement and challenges ahead. Construction and Building Materials 204, 224-243.

Hodicky, K., Sopal, G., Rizkalla, S., Hulin, T., Stang, H., 2015. Experimental and Numerical Investigation of FRP Shear Mechanism for Concrete Sandwich Panels. Journal of Composites for Construction 19, 04014083.

Leonori, M., Vari, A., 2015. L’Influenza della Tipologia di Terreno sui Meccanismi Locali di Collasso degli Edifici in Muratura e Miglioramento Sismico con il Sistema $\mathrm{CAM}^{\circledR}$ [The Influence of the Type of Land on Local Mechanisms of Collapse of Masonry Buildings and Seismic Improvement with the CAM ${ }^{\circledR}$ System], 4th International Workshop on Archaeology, Cryptoportici, Hypogea, Geology, Geotechnics, Geophysics, Rome, Italy, 1-15.

Li, Z., Zhang, X., Shi, Y., Xu, Q., 2019. Experimental Studies on Mitigating Local Damage and Fragments of Unreinforced Masonry Wall under Close-in Explosions. Journal of Performance of Constructed Facilities 33, 04019009.

Llorens, J., 2015. Fabric Structures in Architecture. First ed., Woodhead Publishing, Amsterdam, Boston, Cambridge, Heidelberg, London, New York, Oxford, Paris, San Diego, San Francisco, Singapore, Sydney, Tokyo.

Lonetti, P., Maletta, R., 2018. Dynamic Impact Analysis of Masonry Buildings Subjected to Flood Actions. Engineering Structures 167, $445-458$.

Lorenz, R.F., Stockwell, F.W., 1984. Concrete slab stresses in partial composite beams and girders. Engineering Journal - American Institute of Steel Construction 21, 185-8

Marnetto, R., 2007. Sviluppo ed applicazioni delle tecniche antisismiche presso la società TIS SpA di Roma, Seminario di Studi sui Sistemi e Tecnologie Antisismici, Rome, Italy, 2-27.

Marnetto, R., Vari, A., 2015. Linee Guida-Cuciture Attive per la Muratura: Procedura Generale per la Progettazione, Modellazione, Calcolo e Verifica di Edifici in Muratura Rinforzati con il Sistema di Cucitura Attiva CAM [Active Tying for Masonry: General Procedure for the Design, Modeling, Calculation, and Verification of Masonry Buildings Reinforced with the CAM Active Tying System]; EDIL CAM Sistemi S.r.l.: Rome, Italy. 
Marnetto, R., Vari, A., Marnetto, L., Leonori, M., 2014. Conservare l'Edilizia in Muratura: Il Sistema CAM — Cuciture Attive dei Manufatti [Conserving the Building Heritage in Masonry: The CAM System-Active Confinement of Manufactured Buildings]; Edizioni PREprogetti: Rome, Italy.

Michaloudis, G., Gebbeken, N., 2019. Modeling Masonry Walls under Far-Field and Contact Detonations. International Journal of Impact Engineering 123, 84-97.

Pham, T.M., Hao, H., 2016. Impact Behavior of FRP-Strengthened RC Beams without Stirrups. Journal of Composites for Construction 20,4016011 .

Pourfalah, S., Cotsovos, D.M., Suryanto, B., Moatamedi, M., 2018. Out-of-Plane Behaviour of Masonry Specimens Strengthened with ECC under Impact Loading. Engineering Structures 173, 1002-1018.

Rizkalla, S.H., Lucier, G., Lunn, D., Sennour, L., Gleich, H., Carson, J., 2013. Innovative use of FRP for Sustainable Precast Structures: Using carbon-fiber-reinforced grids in walls and other components. Facade Tectonics Journal 8, 55-63.

Rizkalla, S.H., Tadros, G., 1994. A smart highway bridge in Canada. Concrete International 16, 42-44.

Rousakis, T.C., Panagiotakis, G.D., Archontaki, E.E., Kostopoulos, A.K., 2019. Prismatic RC columns externally confined with FRP sheets and pretensioned basalt fiber ropes under cyclic axial load. Composites Part B: Engineering 163, 96-106.

Russo, P., De Marco, A., Parisi, F., 2019. Failure of Reinforced Concrete and Tuff Stone Masonry Buildings as Consequence of Hydrogen Pipeline Explosions. International Journal of Hydrogen Energy 44, 21067-21079.

Sauer, C., Heine, A., Riedel, W., 2019. Comprehensive Study of Projectile Impact on Lightweight Adobe Masonry. International Journal of Impact Engineering 125, 56-62.

Taher, R., 2019. Building Design for Wind Forces. McGraw-Hill Education, New York, Chicago, San Francisco, Athens, London, Madrid, Mexico City, Milan, New Delhi, Singapore, Sydney, Toronto.

Yossef, M., Chen, A., 2018. A solution considering partial degree of composite action for insulated sandwich panels with general configuration flexible shear connectors. Engineering Structures 162, 135-150. 